\title{
Bestowing Authentic Leadership: A Comparative Study of Two Organisations in Ghana
}

\author{
Justice Owusu-Bempah $^{1}$ \\ ${ }^{1}$ Faculty of Commerce, Lincoln University, Canterbury, New Zealand \\ Correspondence: Justice Owusu-Bempah, Faculty of Commerce, Lincoln University, P.O.BOX 84 Christchurch, \\ Canterbury, New Zealand. Tel: 64-274-471-022. E-mail: Justice.Owusu-Bempah@lincolnuni.ac.nz
}

Received: May 30, 2012 Accepted: September 4, 2012 Online Published: October 1, 2012

doi:10.5539/ijbm.v7n19p31 URL: http://dx.doi.org/10.5539/ijbm.v7n19p31

\begin{abstract}
Bestowing authentic leadership (AL) by leaders and followers in organisations involve the subjective interpretation of the meanings and understandings given to the construct. The likely implication here is that evaluations of the AL construct may vary in different settings. Therefore, the leaders' and followers' constructs of authentic leadership in a public and a private organisation in Ghana were documented and compared using Q methodology. Thirty leaders and followers in each of the two organisations sorted selected statements about authentic leadership. Three factors or types of authentic leadership were identified and named for each of the two settings yielding six different perceptions of authentic leadership. While these results suggest that authentic leadership is idiosyncratic, further analysis showed that some attributes of authentic leadership were common to the organisations. The study concluded that in defining authenticity in leadership in the organisations used for this study in Ghana the following characteristics cannot be overlooked: leader goal orientedness, good listening, leader respect for followers, objectivity and justice, inspirational teaching and leader commitment, God fearing, leader fairness, and leader flexibility. This implies that in designing leadership training programs for organisational success, these attributes, if incorporated could prove helpful.
\end{abstract}

Keywords: authentic leadership, leaders and followers perception, Q method, Ghana

\section{Introduction}

The basis of this study is the identification of some concerns in the authentic leadership (AL) literature regarding the exact make-up of the authentic leadership construct and the several calls made by researchers (Avolio, Gardner, Walumbwa, Luthans, \& May, 2004; Fields, 2007; Luthans \& Avolio, 2003; Vogelgesang, Clapp-Smith, \& Palmer, 2009; Walumbwa, Avolio, Gardner, Wersing, \& Peterson, 2008) for more empirical analysis to address such concerns. A key element of AL is the claim that authenticity is an attribute bestowed on leaders by followers when there is congruence between leaders' espoused values and their actions during leader-follower interactions (Luthans \& Avolio, 2003). Thus leaders and followers come into an organisational setting with values, perceptions and expectations which guide the social interactions that ensues between them. For instance, Lord and Maher (1991) suggest that individuals have prior knowledge of leadership qualities in their memories that is, organized into cognitive schemas as leader prototypes which they rely on when categorizing people into leaders and non-leaders. Therefore, when they encounter a leadership situation later they compare the observed attributes and behaviour to the pre-existing notion held in memory and when the two matches, then the person being observed is categorized as an effective or non-effective leader. Thus, during such interactions, leaders are assessed in terms of followers' own rating systems, perceptions and expectations. Followers compare leaders' stated values with their exhibited behaviours, match the leaders' behaviours with own expectations, and then finally assess whether leader actions produce benefits for the organisation and the followers themselves. In this interactional process of assessing if AL is present, followers bestow the honorary title 'authentic' on the leader when there is congruence between leaders' espoused values and behaviours, when leaders' expectation match follower expectations, and leaders' morality and integrity visibly produces desired benefits to the follower and the organisation.

The underlying assumption here is that follower understanding and meaning of AL construct is important. For leaders to achieve authentic leadership status depends on them having met certain follower expectations of what is authentic. This makes the $\mathrm{AL}$ construct subjective, and therefore, to evaluate it requires understanding 
followers' from their own point of view. However, the current AL literature while recognising the need for more attention to be given to followers does not yet sufficiently address the issue of follower subjectivity in the AL construct.

Another issue of concern is that the current AL theory, which is mainly based on research done in the Western world, suggests that all the desirable authentic leader attributes revealed by such research are universally applicable. For example, authentic leaders are said to be true to themselves (Harter, 2002), and are consistently transparent (Luthans \& Avolio, 2003). They are therefore able to express themselves and act in ways that are consistent with their inner thoughts and feelings. Shamir and Eilam (2005) describe them as originals because they do not fake their actions and intentions, Cammock (2001) prefers to call such leaders great leaders because they lead with the heart. But studies have proven that no two cultures are the same (Den-Hartog, House, Hanges, \& Ruiz-Quintanilla, 1999; Dorfman, 1996; Dorfman et al., 1997; Hofstede, 1980, 2001; House, 2004; Peterson \& Hunt, 1997) and it is likely that follower expectations and perceptions are heavily dependent on their background cultures. The implication here is that cultural context will influence the prioritisation of preferred authentic leader attributes. Therefore, a question exists as to whether leaders and followers in different contexts see authentic leadership differently or not. This is so, because, people give different interpretations and evaluations to given situations encountered.

Similarly, differences in expectations and interpretations will influence assessment of acceptable leadership and organisational practices in different situational or cultural contexts. It is against this background that this study is arguing that if authentic leadership is not a trait but an attribute conferred on leaders based on the congruence between: follower assessment of leaders' espoused values and behaviours, assessment of leader-follower expectations and then finally assessment of leader actions and the direct benefits it produces to the organisation and the followers. There is a greater likelihood to have different meanings given to AL in different situational and/or cultural contexts due to differences in follower subjective understandings and interpretations of situations (Cronshaw \& Lord, 1987; Lord, Foti, \& Phillips, 1982; Lord \& Maher, 1991; Owusu-Bempah, Addison, \& Fairweather, 2011; Phillip \& Lord, 1981).

To be able to address these concerns, it would be worth identifying and comparing the subjective meanings of AL from the points of view of individuals in different cultural and organisational contexts outside the western culture. However, it must be emphasised that Human subjectivity cannot easily be measured using quantitative research approaches and demands in-depth interviews where follow up and engaging questions can be asked for clarification of concepts as they emerge. It must also be noted that such information gathered must be reported from the subjects' own perspective without imposing any external ideas to the meanings as given by subjects. This study therefore, employed the Q method to compare and contrast the meanings given to the AL construct in two different organisations in Ghana a developing nation in sub-Saharan Africa.

\section{Methodology}

The Q-method is a measurement technique introduced by Stephenson (1953) as a way of measuring subjectivity. Therefore, $\mathrm{Q}$ method's strength is in exploring human subjective meanings and the points of view of individuals in a structured and interpretable form (Barry \& Proops, 1999; Brown, 1996; Brown \& Peterson, 1993). It is a method which is best suited when people's views or subjective understandings about a specific phenomenon are to be uncovered (Brown, 1980; Robbins \& Krueger, 2000) because such views are self-referent (Militeello \& Benham, 2010). The $\mathrm{Q}$ method rigorously examines these self-referent views without compromising or confusing it with any external frame of reference. Brown (1996) explained that the Q method measures life as lived from the standpoint of the person living it. That is, Q method can help researchers understand 'why and how people believe in what they do' particularly on topics over which there is much social debate and contestation (such as abortion) (Addams \& Proops, 2000). Using Q method according to Previte et al., (2007), will bring to light people's own perspectives, meanings and opinions on the subject under study.

The main focus of the $\mathrm{Q}$ method is not to find out how prevalent a particular viewpoint is in a given sample but rather to bring an understanding of the contours and subjectivities existing in the views (Stephenson, 1994). These contours according to Cross (2005) come to light because Q method explores varieties of accounts from finite diversities as constructed by people on the given subject.

The Q method consists of five key steps: Collecting relevant ideas, beliefs and opinions concerning the research object; selecting and formulation of a set of meaningful statements; selecting respondents and giving them the statements to sort out in their own way; and analysis and interpretation of data (Brown, 1980).

The concourse in this study was constructed through interviewing 70 diverse people from different sections of a University, and an NGO in Ghana. Respondents were asked to 'describe a good leader they know or have 
known and tell us why he/she considers such a person/people good leader(s)'. As they answered this question they were asked other engaging questions in order to facilitate and extend their responses. This process went on in the selected organisations until such a time that the responses being given by later respondents were similar as those previously given by earlier respondents indicating that no new insights were being found. It is at this point that the initial interviews stopped. A total of 35 statements finally formed the Q sets which were randomly numbered and put on cards for the $\mathrm{Q}$ sorting process by the participants in the two organisations.

For each organisation a variety of staff was selected. For example, at the University, staff from registry, academic departments, and the library, were approached and asked to participate. A staff member who willingly agreed to participate in the study was asked to nominate another staff member of his/her choice. This snowballing continued until 30 participants were selected. The sample size of thirty participants provided sufficient number to allow for many factors (e.g., four factors with five significant loadings). It was observed during this process that some nominees were not necessarily in the same department as the nominator nor were they at the same level. Some of the nominated subjects were found to be either in a higher position than the person who did the nomination or vice versa. This variety of position meant that the sample was diverse.

The respondents were asked to order the Q sets (statements) into three piles; the ones with which they most agreed, the most disagreed and those about which they were neutral. After they were satisfied with their groups they were then asked to select four most agreed statements out their agreed pile. They were then asked to select one statement out of the four that they strongly agree, that was the condition of instruction. The number on the selected statement inserted into the first pile in the Q sort distribution of the $\mathrm{Q}$ sort for the strongly agreed part. The remaining agreed statements were used to fill out other sections of the agreed part of the matrix until that part was completely filled out. This same procedure was followed for the loading of the "disagreed" side of the matrix. The statements with which the respondents neither agreed with nor disagreed (neutral) were used to load the neutral portion of the matrix. Then the respondents were asked to review the completed matrix to make any changes to the arrangement if so desired. The matrix was deemed complete when a respondent was convinced that there was no need to make any further change to the arrangements made in the matrix. As the respondents sorted out the statements, they were invited to comment on the statements first, and then invited to comment on why they ranked the statements on the matrix sheet in the way they did. All their comments were recorded either by way of taking notes during the Q sort or tape recorded and transcribed. Each Q sort lasted between 30 minutes to one hour.

The fourth and fifth steps are analyses and interpretation of the Q sort data respectively. The process begins by entering completely filled out Q sort matrix into the PQ software, a free online software package used for analysing Q data (Schmolck, 2002). The software produces a correlation matrix of all Q sorts. That is, each person's responses are statistically correlated with each other. The correlation coefficient produced is based on the rank ordering of statements in a continuum so that any pair of respondents with similar order will have a high correlation. The magnitude of the correlation coefficients generated by the software indicates the degree of similarity among the various perspectives (ten-Klooster, Visser, \& de-Jong, 2008).

The data for this study were analysed with Principal Component Analysis on a 30 x 30 matrix with varimax rotation. A three factor solution was found to be more preferable as there were sufficient significant loadings of theoretical significance.

\section{Results}

The three authentic leader viewpoints generated by the PQ software for each of the two organisations is presented below. First a brief background characteristic of the participants used for the study is provided followed by the authentic leader perspectives identified by PQ software in each organisation.

\subsection{Background of Study Participants}

The background characteristics of the respondents are varied. In terms of formal education, the University subjects had a relatively higher level of formal education than their NGO counterparts. As much as thirteen out of the 30 subjects in the University as against four in the NGO held masters degree. Four subjects in the University had PhD while none of the subjects in the NGO had gone that far. With regards to bachelors degree, there seem to be a balance between the numbers of subjects in each organisation with a slight edge of those in the NGO over their University counterparts. Seven subjects in the NGO against six in the University held a bachelors degree. While twelve subjects in the NGO against six in the University held tertiary diploma. 


\subsection{University}

\subsubsection{The Consultative Democrat}

The Consultative Democrat derives their name from the belief that there is unity in equality especially when all key players in decision making are consulted, while clear pathways are set to achieve solutions. Authentic leadership for this perspective therefore, centres on leaders' openness to accommodate individual differences and opinions in a firm and fair environment.

Interpretation. The Consultative Democrat believes in systematically laying down plans and developing strategic ways to follow through to the end. For them this is the only basis for getting so many things done without missing the mark. They therefore strongly agree with statement 4 (I prefer leaders who set clear goals for themselves and others, +5 ). However, they believe that the best way to get to the ultimate goal is to find alternative ideas from others which demands opening up to them and/or consulting them for their views on the situation at stake while working together (statement 2: I prefer leaders who are open to other people's ideas and will consult people before making a decision, +4 ). The Consultative Democrat believes that if leaders open up to follower views and opinions, there could be situations where the leader authority might be taken for granted, therefore leaders need to be authoritative by being firm but treat everybody fairly without any bias (statement 12: I prefer leaders who are firm but fair to everybody without any bias whatsoever, +4). Further, in their mind, even though it pays to be open to others but to get more insight and ideas from others demand being transparent in all things (statement 15) and flexible (statement 29: I prefer leaders who are flexible and can find several ways for us to achieve our goals, +3 ) so that when one receives other people's insight and ideas one can easily adapt and incorporate into the original strategies to help improve or enhance the approach of getting to the set target. In addition they want leaders to be inspirational teachers (statement 33: I prefer leaders who teach and inspire me to do more than I normally would, +3 ) so that followers can do more than they normally would by themselves.

On the disagreed side, the Consultative Democrat would not do anything nor just follow leaders because they are their leaders (statement 16: Regardless of the intention and motivation behind their actions I will follow as long as they are my leaders) or regardless of how ethical their decisions may seem (statement 18: I would do anything for leaders who make difficult decisions that are based on high standard of ethical conduct) may be they would want to see where the leader is taking them and how they are going to get there. Fairness and firmness are virtues the Consultative Democrat believes in and therefore they do not think that there should be times leaders should not be objective regardless of how sensitive the issue might be (statement 9: I don't mind if my leader is sometimes not objective as I think that is part of leadership). Again, their strong emphasis on the contributions of other people in achieving set targets, they do not believe that leaders should treat people anyhow regardless of how result oriented that leader might be and therefore their strong disagreement with statement 22 (I admire results oriented leaders regardless of how he/she treat me). As a result of their focus on goals and how to achieve them, they do not think it is wise for leaders to act in ways that pleases an individual (statement 32: I want my leaders to act in ways that pleases me) nor boss over them (statement 28: I like a bossy type of leader) but probably just find ways and means to get to the ultimate goals.

\subsubsection{Leadership by Optimism}

The Leadership by Optimism perspective derive their name from the belief that, there are more good things in life and, therefore, life must be met with a positive attitude. Positive attitude, they believe, must be the foundation to everyday life. Authentic leadership for adherents of this factor centres on maintaining a positive attitude with a strong sense of faith in God and helping others.

Interpretation. The subjects espousing this perspective believe that everything is possible with a positive attitude regardless of prevailing conditions. In their mind, thinking positive has the likely ability to give the individual an inner motivation to move on in life no matter the obstacles that might come along the way. This positive outlook explains their strong agreement with statement 30 (I want positive thinking leaders even in hard times when things seem to be going wrong). In addition they also prefer leaders that are God fearing (statement 26: I prefer a God fearing leader) possibly they believe such leaders would do the right things. In the mind of the Leadership by Optimism factor, a positive attitude to life with the fear of God can help leaders achieve the goals they set for themselves and others (statement 4: I prefer leaders who set clear goals for themselves and others and can help them to achieve the goals). They believe that in order for leaders to get followers to know the direction to follow, it is better for leaders to create the opportunity so that the followers could express themselves by talking while the leaders listen (statement 19: I want my leaders to be good listeners) and also by being inspirational teachers to followers, followers can then do more than they normally would by themselves 
(statement 33: I want leaders who will teach and inspire me to do more than I normally would). In the mind of the Leadership by Optimism factor, goal achievement is very important, and therefore they have no problem accommodating arrogant leaders if they believe such leaders have the required knowledge to help them achieve their goals (statement 5: I don't mind if my leaders are arrogant as long as they are knowledgeable and can help me achieve my goals).

One thing the Leadership by Optimism factor believes is part of leadership regardless of the situation is leader objectivity they therefore strongly object to statement 9 (I don't mind if my leaders are sometimes not objective as I believe that is part of leadership, -3) as this contradicts their beliefs. Again, as mentioned earlier the Leadership by Optimism factor places strong emphasis on having clear goals and knowing how to achieve the goals and this explains their rejection of statement 16 (regardless of the intentions and motivations I will follow as long as they are my leaders, -3). They believe some intentions and motivations may not be honourable or may be for selfish interest and desires. Further, they think it is not necessary for their leaders to act in ways that pleases them alone (statement 32: I want my leaders to act in ways that pleases me, -3) but do what is good for everybody and the organisation. They also value people with integrity and therefore saying one thing and acting differently (statement 14: I don't mind if my leaders does not act according to what they say as I believe that is part of leadership, -4) is seen this perspective as a mark of people without integrity. As mentioned earlier that this perspective believes leaders must listen to followers and also followers listening to leaders. It is therefore not surprising that they do not find it a weakness if a leader tells them how he/she feels (statement 35: I find it a weakness if a leader tells me how he/she feels, -4). Regardless of their high levels of tolerance and accommodation for arrogance, they do not like to be bossed about (statement 28: I prefer a bossy type of leader, $-5)$.

\subsubsection{The Sincere Leader}

The Sincere Leader factor appears more independent and focused, and takes pride in sincerity. They trust their own skills, ideals, talents and knowledge to the level that they believe what they have is sufficient to see them through any situation they meet at work. The meaning of authentic leadership to adherents of this perspective,centre around having the independence and freedom to work by using one's own initiatives, ideas and skills in a sincere, truthful and open environment.

Interpretation. As should be apparent, the Sincere Leader like the Consultative Democrat prefers setting clear goals for themselves and others (statement 4: I prefer leaders who can set clear goals for themselves and others, and then help them to reach them, +5 ) but for quite different reasons. In the mind of the Sincere Leader, leaders can attain success in terms of achieving desired goals only when they tell the truth about everything (statement 20: I prefer leaders who tell truth about everything including admitting when they don't know something, +4$)$ and act according to their word (statement 13: I want leaders who act according to what they say, +3 ) at all times and in all situations. These two conditions according to the Sincere Leader perhaps involve some level of commitment if results are to be achieved. This therefore forms the basis of their strong agreement with statement 31 (commitment of leaders to the work and to the people working with them is something I desire in my leader, $+4)$. In the mind of the Sincere Leader, working with people demands respecting their views and differences regardless of whether one agrees with them or not. They therefore strongly agree with fact that leaders' must show respect to people and what they stand for (statement 11: I prefer leaders who will respect me for who I am and what I stand for, regardless of whether they agree or not, +3$)$. The Sincere Leader thinks that there are several ways to goal achievement but the key is flexibility in terms of seeking and adopting other good suggestions that might come from other people, hence their agreement with statement 29 (I prefer leaders who are flexible and can find several ways in achieving our goals, +3$)$.

The very nature of the Sincere Leader is the confidence they have in themselves and their belief in their own skills, knowledge and ideas. This explains why they believe they do not need to be taught or inspired before they would do more than they normally would (statement 33: I want leaders who will teach and inspire me to do more than I normally would). They think they are already motivated and always do more and therefore there is no need for them to be taught and inspired before they give their best. The Sincere Leader does not want to be bossed on (statement 28: I like a bossy type of leader) nor be treated anyhow (statement 22: I admire result oriented leaders regardless of how they treat me) regardless of how results oriented such person may be. Because the Sincere Leader believes in truth in all things and all situations, they do not prefer the exercise of moderations when being dealt with (statement 23: I do not want leaders to be too blunt; some moderation is preferable) but wants things blunt as they are. Further, because they believe they know who they are already so they think there is no need to have lessons from anyone to identify who they are anymore. This could therefore be the basis for their strong disagreement with statement 1 (I like leaders who are confident about who they are 
and can help me be same). The Sincere Leader does not tolerate arrogance especially if people believe they are knowledgeable and could help them achieve their aims. Such a picture is painted as they disagree with statement 5 (I don't mind if my leaders are arrogant as long as they are knowledgeable and can help me achieve my goal).

\subsection{Nongovernmental Organisation}

\subsubsection{The Independent Enthusiast}

The Independent Enthusiast perspective derived the name from their passion to do things independently by laying out the roadmaps to achieving set goals while helping others do the same. Authentic leadership for proponents of the Independent Enthusiast is, therefore, in the leaders' role performance, i.e.,- setting goals for themselves and others, creating independence and equal opportunities for followers to act while they (leaders) direct and empower followers towards goal achievement.

Interpretation. The Independent Enthusiast believes leaders should set clear and specific goals for themselves and their followers and help followers achieve the goals they set for them (Statement 4: I prefer leaders who can set clear goals for themselves and others and help them to reach them, +5$)$. In the mind of the Independent Enthusiast achieving goals, demands positive thinking by leaders regardless of the prevailing conditions therefore they are in strong agreement with statement 30 (I want positive thinking leaders even in hard times when things seem to be going wrong, +4). They believe that if leaders are God fearing (statement 26: I prefer a God fearing leader, +4 ) they can be inspirational teachers (statement 33: I want leaders who would teach and inspire me to do more than I normally would, +3), good listeners (Statement 19: I want my leaders to be good listeners, +3) and transparent (statement 15: I want leaders who speak transparently about everything without any hidden motives, +3). That is, the Independent Enthusiast prefers goal oriented leaders who would do whatever it takes to achieve set goals. But in their mind, such leaders must be God fearing, secondly, be inspirational teachers, good listeners and transparent in all their dealings with a positive attitude towards situations.

Regardless of the preference and interest in leaders who achieve goals, the Independent Enthusiast does not favour arrogant (statement 5: I don't mind if my leaders are arrogant as long as they are knowledgeable and can help me achieve my goals, -3) or bossiness (statement 28: I like bossy type of leaders, -5) leaders. However, they believe that objectivity (statement 9: I don't mind if my leaders are sometimes not objective especially about sensitive issues as I think that is part of leadership, -3) and integrity (statement 14: I don't mind if my leader does not act according to what they say as I believe that is part of leadership, -3) are essential parts of leadership no matter what the situation, therefore their strong disagreement with those statements which framed these topics negatively. As a result of their belief in creating an open and fair environment for everybody by leaders, the Independent Enthusiast would not appreciate the leader acting in ways that pleases people (statement 32: I want my leaders to act in ways that pleases me, -4) as this is against the Independent Enthusiast's ideological stance.

\subsubsection{The Social Democrat}

The Social Democrat perspective derived their name from the belief that decision making must be made collectively while every employee must have equal access and benefit of organisational structures and resources. Authentic leadership for adherents of this factor therefore, is centred on fairness and a firm environment where everybody had equal access to resources and equal opportunities.

Interpretation. The subjects loaded on this factor are concerned about each member of the community receiving fair treatment without being discriminated against. This attitude is forms the basis for their strong agreement to statement 12 (I prefer leaders who are firm but fair to everybody without any bias whatsoever, +5). Agreeing strongly to statement 12 shows how the Social Democrat cherishes individual contributions to the overall success of the organisation if each person is given the chance by leaders. In the mind of the Social Democrat, leaders can give each community member a chance only if everybody is given a fair hearing (statement 19: $I$ want my leaders to be good listeners, +3) while their ideas taken on board. If leaders do this, then the Social Democrat sees them as being open and consulting (statement 2: I prefer leaders who are open to others and would consult people before making decisions, +4). In mind of the Social Democrat, if leaders tell the truth about everything (statement 20: I prefer leaders who tell the truth about everything, including admitting they don't know something, +4) and are God fearing (statement 26: I prefer a God fearing leader), they can set clear goals for themselves and others (statement 4: I prefer leaders who set clear goals for themselves and others and help them reach them, +3$)$. 
On the disagreement side, statement 14 (not acting according to one's word, -3) strongly contradicts the Social Democrat's strong emphasis on honesty and therefore it is not surprising that they strongly object to statements that negatively framed this virtue. Also, they again indicated their appreciation of each individual's contribution because they feel that it is the combined effect of everybody's potentials, abilities and capabilities, that brings success to organisations and therefore everybody must be respected (Statement 22: I admire results oriented leaders regardless of how they treat me, -3 ).

It is their belief that leaders must set clear goals for themselves and others as this shows where they are going and how to get there. Therefore, disagreeing with statement 16 (Regardless of the intentions and motivations behind their actions I will follow as long as they are my leaders, -3) confirms this belief of first wanting to know where they are going through the set goals. They also indicated that they would not do anything for leaders regardless of whether or not their decisions are based on ethics (statement18: I would do anything for leaders who make difficult decisions that are based on high standards of ethical conduct, -4). This also affirms their desire to first and foremost knowing where they are going and how to get there all other things are probably secondary. Further, it is also expected that their strong emphasis on equality would definitely make them disagree with being bossed about (statement 28: I prefer a bossy type of leader, -5) as they see this as preventing equality. Again, their strong trust in people's capabilities and abilities could explain why they believe person should be able to handle their own affairs without having to discuss it with leaders therefore their strong disagreement with statement 27 (I look for leaders I can discuss my personal issues with, -3).

\subsubsection{The Independent Novice}

The Independent Novice believes they need training in order to meet the normal requirements of being regarded as mature and equal participants in their chosen field. But, they want to be active participants in the training process. Authentic leadership for the adherents of this factor would be seen when leaders teach and inspire followers while allowing followers to contribute to the training, that is, by being giving.

Interpretation. The Independent Novice is a learner with a main focus of needing as much knowledge, ideas and/or information as possible from others (in this case a leader). They however do not want just any knowledge, but a well organised and structured knowledge with specific emphasis on helping them achieve specific target. Having this mindset formed the basis of their strong agreement with statement 33 (I want leaders who will teach and inspire me to do more than I normally would, +5 ) and statement 4 (I prefer leaders who can set clear goals for themselves and others, and help us to reach the goals, +4). Their strong agreement with statement $17(I$ prefer leaders who solicit views even if they challenge their deeply held ideas, +4) also portray them not as passive recipients of the training they desire but as active participants in the exchanges that go on during the training period. In the mind of the Independent Novice, leaders must be able to solicit followers' views even if such views contradicts with the leaders held ideas during their interactions (statement 17). This agreement also confirms their active participation when being taught and inspired.

In their mind, leaders who teach and inspire followers show commitment. Therefore it is expected that they will agree strongly with statement 31 (Commitment of leaders to the work and to those working with them is something I desire in my leader, +4). Further, because of their quest for applicable knowledge, the Independent Novice is deeply concerned about how they fare when being assessed of their performance so they prefer leaders who are firm but fair to everybody without any bias (statement 12: I prefer leaders who are firm but fair to everybody without any bias whatsoever, +3 ), thinking that such leaders can give this kind of assessment.

More revealing of the Independent Novice is the standards they seem to have for their coaches (leaders). They want a trainer who is bold and confident and having independent mind whereby they can make a point and stand solidly for it i.e. is being sure of what is being communicated without wavering or having a second thought as this directly correspond with their strong agreement with statement 6 (Assertiveness, charisma and strong mindedness are attributes I always desired in my leaders, +3 ).

On the disagreement side, though the Independent Novice desires to acquire as much knowledge as possible but not from arrogant leaders (statement 5: I don't mind if my leaders are arrogant as long as they are knowledgeable and can help me achieve my goals, -3) nor those who say one thing and do another (statement 14:I don't mind if a leader does not act according to what they say as I believe that is part of leadership, -3), neither do they want to be taught by leaders who are not objective (statement 9: I don't mind if my leader is not objective especially about sensitive issues as I think that is part of leadership, -3). Again, they would not follow somebody for following sake (statement 16: Regardless of the intentions and motivations behind their actions I will follow as long as they are my leaders, -4) unless they probably know that they are going to get a certain kind of desired training to their benefit, they therefore would like to know this first before following. Also, 
because they want to take advantage of every opportunity to learn, they do not think it is a weakness if a leader tells them how they feel (statement 35: I find it a weakness if a leader tells me how he/she feels, -4). Regardless of their determination to learn and mature, it is interesting to note that the Independent Novice do not want leaders who will please them (statement 32: I want leaders to act in ways that pleases me, -5) but would possibly prefer those who will be straight up with them.

\subsection{Consensus Statements}

All subjects used in Ghana strongly prefer leaders who can set clear goals for themselves and others and help them to achieve the goals (statement 4). From the interpretation, it was obvious that all the subjects believe that setting clear goals show that the leader knows where he/she is going and therefore will be easier to direct followers along that direction. By this agreement it could be said that the Ghana subjects probably want to know exactly where their leaders are taking them and the likely outcome and possibly the benefit they may derive out of that. Or it could be that they just have the idea that leadership is about setting and achieving goals. Statement 26 (I prefer a God fearing leader) also appears to appeal to the subjects as it enjoyed a positive image amongst them all. This could be attributed to the high religiosity and the belief in God as the Supreme Being and the controller of everything by the people of Ghana.

And therefore the subjects believe that having set clear goals, one needs God's direction, guidance and strength to carry him/her through to a successful end as they believe that all good things is given by him. Leader flexibility (statement 29) is an attribute which is also highly preferred by all the subjects. As discussed in the interpretation, perhaps all the subjects believe that for leaders to be able to achieve goals they demand some flexibility in modifying their original ideas. Probably they associate flexibility to taking on board follower suggesting and contributions in decision making. Firm but fair (statement 12) was positively received by all the subjects as something they all preferred. The subjects believe that being flexible also demands exerting some authority to prevent followers for taken leader for granted. They therefore want leaders to be authoritative and at the same time fair to everybody without any bias. In their mind when followers see such fairness they might be encouraged to contribute more ideas. This shows some kind of cyclical effect with both followers and leaders winning.

\subsection{Meta Analysis}

An examination of all the factors shows some commonalities within the preferred AL attributes across the organisations. However, we have to verify such commonalities and make conclusions by statistically testing whether or not such identified commonalities are significant. It is for this reason that a meta-analysis in the form of second-order factor analysis was performed on the factors. All 35 statements were reloaded into the PQ software and the factor arrays of each factor in each of the organisation were re-entered as individual sorts. Using the formula $1 / \sqrt{ } \mathrm{n} \times 2.58$ to check for possible factors that can be generated from the unrotated factor matrix resulted in a two-factor solution, as two of the values for the second-order factor analysis for unrotated factor matrix were found to be equal to or above 0.45 .

The second-order factor analysis results showed that the NGO factor 2 loaded significantly on Factor A (Appendix B) whereas factor 1 and 3 loaded significantly on Factor B. A reverse picture is painted among the University factors. Whereas factors 1 and 3 of the University are loaded significantly on Factor A, only factor 2 is loaded significantly on Factor B. Critically examining the emerging statements in factors A and B, the preferred AL attributes that emerged for Ghanaian factors includes; leader goal orientedness (statement 4), good listening (statement 19), leader respect for followers (statement 20), objectivity and justice (statement 8), inspirational teaching (statement 33) and leader commitment (statement 31), God fearing (statement 26), leader fairness (statement 12), and leader flexibility (statement 29).

However, there were some preferred AL attributes that were specific to the NGO factors: leaders being knowledgeable and having the ability to followers achieve their goals regardless of whether or not the leader is arrogant (statement 6), whereas the preferred AL attributes specific to the University factors was leaders being confident in whom they are (statement 1).

\section{Implications}

This study offers several significant implications for AL theory. Following from the above, it must be noted that subjects in Ghana would rate their leaders at their respective work places based on their particular understanding of the meaning of authenticity in leaders. Therefore, the meaning of authenticity found in this study must be given due consideration by the organisations as this can go a long way to increase desired organisational outcomes. The argument here is that, the identified authentic leader attributes in this study are positive 
expectations the subjects in this study would like their leaders to exhibit in the leader-follower exchanges at their work place. If the subjects in this study find these attributes in their leader at the work place, they would feel comfortable building a good and positive personal relationship with their leader. Such relationships are basically founded on trust. This is because some of the preferred identified authentic leadership attributes in this study e.g., openness and fairness have been identified in the trust literature as being antecedents to building trust.

Two attributes that were specifically preferred by the all the Ghana subjects that the authentic leadership literature is silent over were God fearing and objectivity and justice. The participants believe that being God fearing forms a core part of authenticity in leaders. This is because they feel that if a leader is God fearing he/she will possess all the desirable qualities such as being understanding, empathic, supportive, and encouraging to mention a few. Ghana, a high power distance country is classified as highly religious (Hofstede, 1980). It may be that the ability to fear a common God may help bridge this power gap - the distance between leaders and followers pales into insignificance when compared to the distance between them both and their God. This may well contribute to the importance of this factor. Also, in Ghana, God is regarded as a caring and benevolent Supreme Being and therefore if a leader is presumed to be God fearing then possibly he/she is perceived to exhibit these benevolent characteristic associated with God. This is consistent with the human oriented leadership findings of Wanasika et al., (2010) in sub Saharan Africa (which Ghana forms part) that when leaders are perceived as being supportive and considerate exhibiting compassion and benevolence for followers they are regarded as great leaders in sub Saharan Africa.

Objectivity and justice was another preferred authentic leader attribute specific to the Ghana subjects. The subjects feel that for a leader to be authentic, he/she must be free from his/her own biases in making decisions and must be fair and just in every situation. This has been identified in the authentic leadership literature as an attribute of authentic leaders.

\section{Conclusion and Future Research}

In this paper, I have compared the subjective interpretations of respondents in two organisations regarding authentic leadership. Based on the findings, this study concludes that one cannot describe authentic leadership in the organisations used in Ghana without the mention of leader behavioural characteristics such as; leader goal orientedness, good listening, leader respect for followers, objectivity and justice, inspirational teaching and leader commitment, God fearing, leader fairness, and leader flexibility. By these findings, this study, apart from validating some of the AL attributes in the AL literature, also extends AL theory relative to the meaning giving to AL. For example, God fearing, inspirational teaching and justice are either not in the AL literature or they are implicitly explained. But this study found them as important components in the meanings given to AL by the respondents. Implicit in the majority of extant, AL theory is the notion that AL theory has been argued as being universally applicable in all contexts and cultures. This study supports the commonly preferred AL attributes as indicated in the $\mathrm{AL}$ theory but extends it to include some other preferred attributes that are either contextually/culturally specific. That means though there are some AL attributes that are commonly preferred in different contexts but there are others that would be contextually specific. Against this background, this paper further concludes that if organisations could identify such contextually preferred attributes and incorporate them in their training programs for leaders and would be leaders, desirable organisational outcomes could be achieved.

In the future, studies could investigate the subjective meanings given to AL in businesses instead and other informal organisations and compare the findings. Other studies can compare multinational, international and national organisations to validate some of these findings.

\section{Acknowledgements}

We would like to thank all of the anonymous participants who gave up valuable time and energy to complete $\mathrm{Q}$ sorts and provide us their views about authentic leadership. We are very grateful especially to Lincoln University and Richmond New Zealand Trust Limited for their support in allowing their staff to participate in this study. We would also like to express our sincerest appreciation again to Lincoln University for providing the funds to cater for travel expenses during the data gathering process and to all who made various contributions in the way of advising, suggesting or correcting this paper we say thank you very much. 


\section{References}

Addams, H., \& Proops, J. (2000). Social discourse and environmental policy: An application of Q methodology. Cheltenham Edward Elgar.

Avolio, B., Gardner, W., Walumbwa, F., Luthans, F., \& May, D. (2004). Unlocking the mask: A look at the process by which authentic leaders impact follower attitudes and behaviors. Leadership Quarterly, 15(6), 801-823. http://dx.doi.org/10.1016/j.leaqua.2004.09.003

Barry, J., \& Proops, J. (1999). Seeking sustainability discourse with Q methodology. Ecological Economics, 26(2), 387-403.

Brown, S. R. (1980). Political subjectivity: applications of $Q$ method in Political Science. New Haven: Yale University Press.

Brown, S. R. (1996). Q methodology as the foundation for a science of subjectivity. Operant Subjectivity, 18, $1-16$.

Brown, S. R., \& Peterson, R. A. (1993). Antecedents and consequences of sales person job satisfaction. Meta-analysis and assessment of causal effects. Journal of Marketing Research, 30, 63-77. http://dx.doi.org/10.2307/3172514

Cammock, P. (2001). The dance of leadership. Auckland: Pearson Education Ltd.

Cronshaw, S. F., \& Lord, R. G. (1987). Effects of categorisation, attribution and encoding process on leadership perceptions. Journal of Applied Psychology, 72, 97-106. http://dx.doi.org/10.1037/0021-9010.72.1.97

Cross, R. M. (2005). Exploring attitudes: the case for Q methodology. Health Education Reseach, Theory and Practice, 20(2), 206-213.

Den-Hartog, D. N., House, R. J., Hanges, P. J., \& Ruiz-Quintanilla. (1999). Culture specific and cross-cultural generalizable implicit leadership theories: are attributes of charismatic/transformational leadership universally endorsed? Leadership Quarterly, 10(2), 219-256.

Dorfman, P. W. (1996). International and cross-cultural leadership. In B. J. Punnet \& O. Shekar (Eds.), Handbook for international management research (pp. 267-331). Oxford: Blackwell.

Dorfman, P. W., Howell, J. P., Hibino, S., Lee, J. K., Tate, U., \& Bautista, A. (1997). Leadership in western and Asian countries: commonalities and differences in effective leadership processess across cultures. Leadership Quarterly, 8(3), 233-274. http://dx.doi.org/10.1016/S1048-9843(97)90003-5

Fields, D. L. (2007). Determinants of follower perceptions of a leader's authenticity and integrity. European Management Journal, 25(3), 195-206. http://dx.doi.org/10.1016/j.emj.2007.04.005

Harter, S. (2002). Authenticity In C. R. Snyder \& S. J. Lopez (Eds.), Handbook of positive psychology. Oxford, UK: Oxford University Press.

Hofstede, G. (1980). Motivation, leadership and organisation. Do American theories apply abroad? Organisational Dynamics, 42-63. http://dx.doi.org/10.1016/0090-2616(80)90013-3

Hofstede, G. (2001). Culture's consequences: comparing values, behaviours, institutions and organisations across nations. USA: Sage Publications Inc.

House, R. J. (2004). Illustrative examples of GLOBE findings. In R. J. House, P. J. Hanges, M. Javidan, P. W. Dorfman \& V. Gupta (Eds.), Culture, leadership and organisations: The GLOBE study of 62 societies (pp. 3-7). Thousand Oaks, California: Sage Publications Inc.

Lord, R. G., \& Maher, K. J. (1991). Leadership and information processing: linking perceptions and performance. New York: Routledge.

Lord, R. G., Foti, R. J., \& Phillips, J. S. (1982). A theory of leadership categorisation. In J. G. Hunt, U. Sekaran \& C. A. Schriesheim (Eds.), Leadership: beyond establishment views (pp. 104-121). Carbondale, Illinois: Southern Illinois University Press.

Luthans, F., \& Avolio, B. J. (2003). Authentic leadership development. In K. S. Cameron, J. E. Dutton \& R. E. Quinn (Eds.), Positive Organisational Scholarship: foundations of a new discipline (pp. 241-258). San Francisco: Berrett-Koehler.

Militeello, M., \& Benham, M. K. P. (2010). Sorting out' collective leadership: How Q methodology can be used to evaluate leadership development. The Leadership Quarterly, 21, 620-632. 
http://dx.doi.org/10.1016/j.leaqua.2010.06.005

Owusu-Bempah, J., Addison, R., \& Fairweather, J. (2011). Does follower subjectivity matter in defining authentic leadership? A call for qualitative research. Asia Pacific Journal of Business and Management, 2(2), 1-25.

Peterson, M. F., \& Hunt, J. G. (1997). International perspective on international leadership. Leadership Quarterly, 8(3), 203-231. http://dx.doi.org/10.1016/S1048-9843(97)90002-3

Phillip, J. S., \& Lord, R. G. (1981). Causal attributions and perceptions of leadership. Organisational Behaviour and Human Performance, 28, 58-83.

Previte, J., Pini, B., \& Haslam-McKenzie, F. (2007). Q methodology and rural research. Sociologia Ruralis, 47(2), 135-147. http://dx.doi.org/10.1111/j.1467-9523.2007.00433.x

Robbins, P., \& Krueger, R. (2000). Beyond bias? The promise and limits of Q method in human geography. Professional Geographer, 52(4), 636-648. http://dx.doi.org/10.1111/0033-0124.00252

Schmolck, P. (2002). Freely available to download Retrieved July 5, 2010, Retrieved from http://www.Irz.de/-schmolck/qmethod

Shamir, B., \& Eilam, G. (2005). What's your story? life-stories approach to authentic leadership development. The Leadership Quarterly, 16, 395-417. http://dx.doi.org/10.1016/j.leaqua.2005.03.005

Stephenson, W. (1953). The study of behaviour: $Q$ technique and its methodology. Chicago: University of Chicago Press.

Stephenson, W. (1994). Introduction to Q methodology. Operant Subjectivity, 17, 1-2.

Ten-Klooster, P. M., Visser, M., \& de-Jong, D. T. (2008). Comparing two image research instruments: the Q-sort method versus the likert attitude questionnaire. Food Quality and Preference, 19, 511-518. http://dx.doi.org/10.1016/j.foodqual.2008.02.007

Vogelgesang, G., Clapp-Smith, R., \& Palmer, N. (2009). The role of authentic leadership and cultural intelligence in cross-cultural contexts: an objectivist perspective. International Journal of Leadership studies, 5(2), 102-117.

Walumbwa, F., Avolio, B. J., Gardner, W. L., Wersing, T. S., \& Peterson, S. J. (2008). Authentic leadership: development and validation of a theory-base measure. Journal of Management, 34(1), 89-126. http://dx.doi.org/10.1177/0149206307308913

Wanasika, I., Howell, J. P., Littrell, R., \& Dorfman, P. (2010). Managerial leadership and culture in sub-saharan Africa. http://dx.doi.org/10.1016/j.jwb.2010.11.004 


\section{Appendix A}

Table 1. Raw score for consensus statements for each factor for both NGO and university

\begin{tabular}{|c|c|c|c|c|c|c|}
\hline & \multicolumn{3}{|c|}{$\begin{array}{c}\text { University } \\
\text { (Factors) }\end{array}$} & \multicolumn{3}{|c|}{$\begin{array}{c}\text { NGO } \\
\text { (Factors) }\end{array}$} \\
\hline & 1 & 2 & 3 & 1 & 2 & 3 \\
\hline 26. I prefer a God fearing leader & 1 & 5 & 1 & 4 & 4 & 2 \\
\hline $\begin{array}{l}\text { 4. I prefer leaders who set clear } \\
\text { goals for themselves and others } \\
\text { and help them achieve }\end{array}$ & 5 & 4 & 5 & 5 & 3 & 5 \\
\hline $\begin{array}{l}\text { 29. I prefer leaders who are } \\
\text { flexible and can find several ways } \\
\text { for us to achieve our aim }\end{array}$ & 3 & 2 & 4 & 3 & 2 & 2 \\
\hline $\begin{array}{l}\text { 12. I prefer leaders who are firm } \\
\text { but fair to everybody without any } \\
\text { bias whatsoever }\end{array}$ & 4 & 0 & 2 & 1 & 5 & 3 \\
\hline
\end{tabular}

Appendix B

Table 2. Pearson's correlation between the Ghana factors

\begin{tabular}{ccccc}
\hline & & \multicolumn{3}{c}{ University } \\
\hline \multirow{3}{*}{ NGO } & IE & CD & LO & SL \\
& SD & $0.77^{*}$ & $0.73^{*}$ & 0.40 \\
& IN & $0.75^{*}$ & 0.39 & 0.47 \\
& & 0.55 & 0.55 & 0.42
\end{tabular}

Significant $\mathrm{p}<.01$

Table 3. Second-order factor analysis of Ghana factors

\begin{tabular}{llll}
\hline & & A & B \\
\hline \multirow{2}{*}{ NGO } & 1 & 0.53 & $0.80^{*}$ \\
& 2 & $0.81^{*}$ & 0.36 \\
& 3 & 0.45 & $0.69^{*}$ \\
\multirow{2}{*}{ University } & 1 & $0.75^{*}$ & 0.48 \\
& 2 & 0.38 & $0.93^{*}$ \\
& 3 & $0.84^{*}$ & 0.05
\end{tabular}

Significant $\mathrm{p}<.01$ 


\section{Appendix C}

The final Q sets used for the Q sorts for the study

I like confident leaders who can make their point and stand by it regardless of what others think

I want leaders who are confident in representing the organisation and their role in it

I prefer leaders who are open to other people's ideas and will consult people before making a decision

Encouragement and support in everything are things I expect from leaders

I prefer leaders who can set clear goals for themselves and others and guide them to reach the set goals

I don't mind if my leaders are arrogant as long as they are knowledgeable and can help me achieve my goals

Assertiveness, charisma and strong mindedness are attributes I always desired in my leaders

I would like a leader who is non-judgmental about me and others

Objectivity and justice are two of the most important things I want to see in my leaders

I don't mind if my leader is sometimes not objective, especially about sensitive issues as I

think this is part of leadership

I don't mind if my leader does not act according to what they say as I believe that is part of leadership

I want leaders who are open to my ideas and appreciate what I can do

I prefer leaders who will respect me for who I am and what I stand for, regardless of whether they agree or not

I prefer leaders who are firm but fair to everybody without any bias whatsoever

I want leaders who act according to what they say

I don't mind if a leader does not act according to they say as I believe that is part of leadership

I want leaders who speak transparently about everything without any hidden motives regardless of how it feels

Regardless of the intentions or motivations behind their actions I will follow as long as they are my leaders

I prefer leaders who solicit views even if they challenge their deeply held ideas

I would do anything for leaders who make difficult decisions that are based on high standards of ethical conduct

I want my leaders to be good listeners

I prefer leaders who tell the truth about everything, including admitting when they have limited knowledge about something

I look for a leader, who I can easily approach and discuss issues with

I want to know the real intentions or motivations behind every action my leader takes

I do not want leaders who will be too blunt, some moderation is preferable

I keep my relationship with my leader at a purely professional level, nothing more

I admire results oriented leaders regardless of how he/she treats me 
I find it a weakness if a leader tell me how he/she feels

I look for leaders I can discuss my personal issues

I like a bossy type of leader

I prefer leaders who are flexible and can find several ways and resources for us to achieve our goal

I want positive thinking leaders even in hard times when things seem to be going wrong

Commitment of leaders to the work and to those working with them is something I desire in my leader

I want my leader to act in ways that pleases me

I prefer a God-fearing leader

I want leaders who would be like a parent to me at the work place 